\title{
Electric Power Systems Research
}

\author{
Ying-Yi Hong
}

Department of Electrical Engineering, Chung Yuan Christian University, Taoyuan City 32023, Taiwan; yyhong@ee.cycu.edu.tw; Tel.: +886-3-265-1200

Academic Editor: Enrico Sciubba

Received: 3 October 2016; Accepted: 11 October 2016; Published: 15 October 2016

This book contains articles [1-22] that were accepted for publication in a Special Issue of Energies on the subject of "Electric Power Systems Research".

Customers request electric utilities to deliver electric power in a stable, reliable, secure, and sustainable manner from a generation system through transmission and distribution systems to end-users. Consequently, the need to develop advanced technologies and novel methods applied to the modern power system is essential. Recently, the concept of smart grids that incorporate renewable generation, power electronics-based facilities, and information/communication technologies has been receiving increasing attention.

"Electric Power Systems Research" is a special issue of Energies for the publication of original papers about the generation, transmission, distribution, and utilization of electrical energy. This special issue presents important results of work on power systems. Papers can present applied research, the development of new procedures or components, an original application of existing knowledge, or new design approaches.

Authors were invited to submit papers on "Electric Power Systems Research", including, but not limited to, the following areas:

(1) Power system stability;

(2) Power system reliability;

(3) Flexible alternating current transmission systems (FACTS) applied to power systems;

(4) Application of optimization methods to power systems;

(5) Architectures and models of smart grids;

(6) Power market;

(7) Control, operation, and planning of distributed generation resources;

(8) Smart home with energy management systems;

(9) Microgrids and active distribution networks;

(10) Virtual power plants and demand response.

The status of this special issue is as follows. A total of 72 articles were submitted, but only 22 articles were accepted for publication following a strict review process. The mean processing time was 78.39 days. Among the published 22 articles, the numbers of research and review articles are 21 and 1 , respectively. The authors of the published articles are in Asian, North American, and European countries-specifically, China (11), Korea (6), USA (3), Spain (2), Taiwan (2), Japan (1), Canada (1), and Ireland (1) (the number in parentheses is the number of papers; a paper may have authors from different countries).

These 22 published papers can be classified into five categories, which are generation systems, transmission systems, distribution systems, end-users, and the power market, as shown in Figure 1. The generation category covers distributed generation, stability, dynamics, and transients [1-4, $8,10,13,15-17]$. The transmission system category covers high-voltage direct current (HVDC), 
FACTS, and thermal standards $[5,8,12,21]$. The distribution system category covers many topics, such as voltage control, network reconfiguration, microgrids, power quality, smart distribution, and multi-agents $[6,10,11,14,20,22]$. The end-users category covers demand response, frequency control, and critical peak pricing $[7,15,18,19]$. The power market category deals with problems of contract design and load serving entities $[9,18]$. Several papers $[8,10,15,18]$ cover more than one subject.

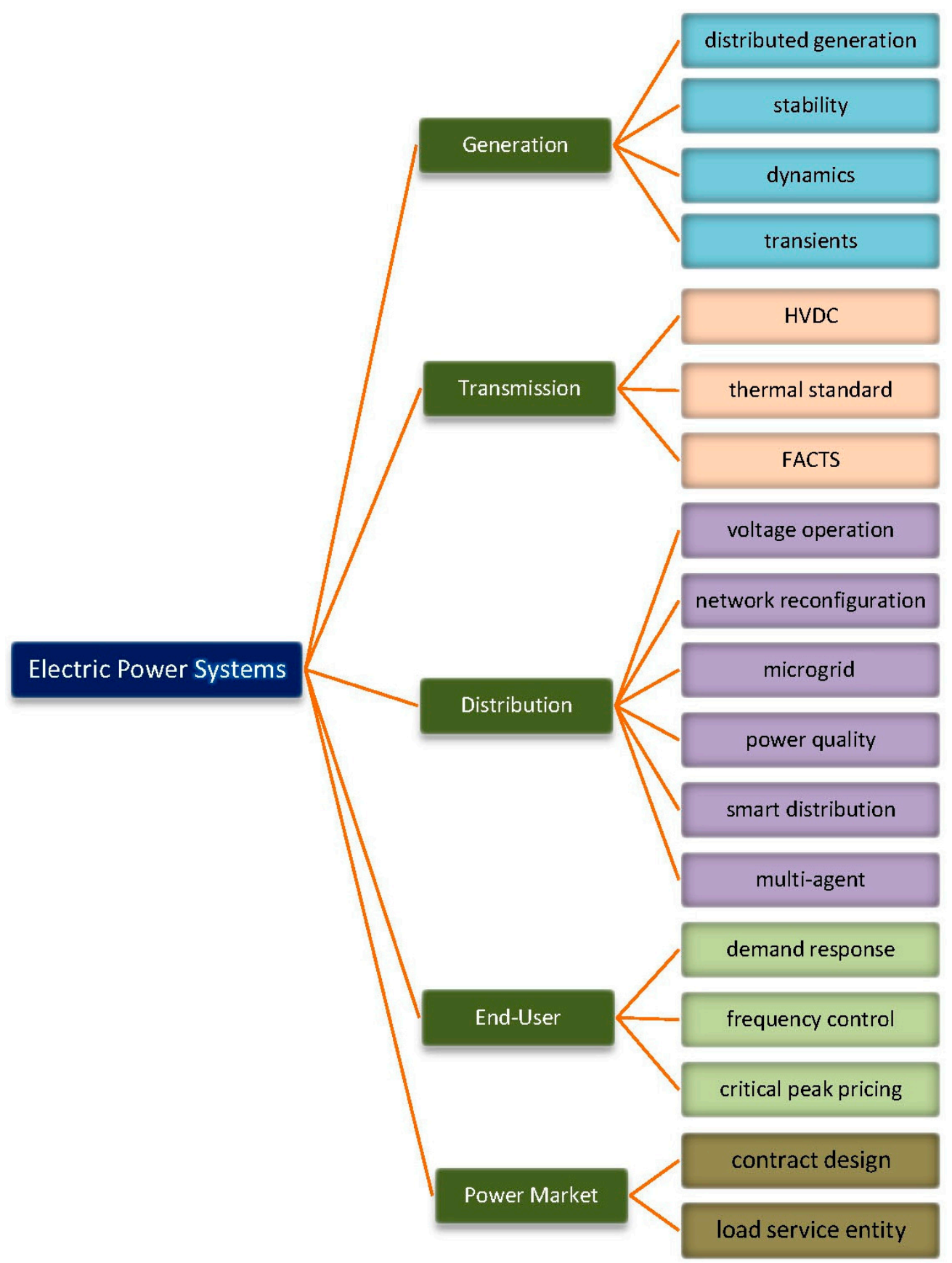

Figure 1. Five categories of subjects covered in special issue, "Electric Power Systems Research". HVDC: high-voltage direct current; and FACTS: flexible alternating current transmission systems.

The generation category included the most papers while the power market category included the fewest. Not all topics on which submissions were invited were accepted for publication. For example, articles related to power system reliability, the architecture of smart grids, and virtual power plants 
were not published in this special issue, because of the rigorous review process, which resulted in the rejection of 50 submitted papers.

The task of editing and reviewing papers for this collection was academically rewarding. The effort and input of the staff members and reviewers are greatly appreciated.

Conflicts of Interest: The authors declare no conflict of interest.

\section{References}

1. Hu, B.; Sun, J.; Ding, L.; Liu, X.; Wang, X. Dynamic equivalent modeling for small and medium hydropower generator group based on measurements. Energies 2016, 9, 362. [CrossRef]

2. Huang, C.; Yue, D.; Xie, X.; Xie, J. Anti-windup load frequency controller design for multi-area power system with generation rate constraint. Energies 2016, 9, 330. [CrossRef]

3. Wu, G.; Ju, P.; Song, X.; Xie, C.; Zhong, W. Interaction and coordination among nuclear power plants, power grids and their protection systems. Energies 2016, 9, 306. [CrossRef]

4. Zhao, Y.; Li, Z.; Nie, Y. A time-frequency analysis method for low frequency oscillation signals using resonance-based sparse signal decomposition and a frequency slice wavelet transform. Energies 2016, 9, 151. [CrossRef]

5. Oh, S.; Chae, S. A co-simulation framework for power system analysis. Energies 2016, 9, 131. [CrossRef]

6. Sima, W.; Zou, M.; Yang, Q.; Yang, M.; Li, L. Field experiments on $10 \mathrm{kV}$ switching shunt capacitor banks using ordinary and phase-controlled vacuum circuit breakers. Energies 2016, 9, 88. [CrossRef]

7. Yang, S.; Zeng, D.; Ding, H.; Yao, J.; Wang, K.; Li, Y. Multi-objective demand response model considering the probabilistic characteristic of price elastic load. Energies 2016, 9, 80. [CrossRef]

8. Yoon, M.; Yoon, Y.; Jang, G. A study on maximum wind power penetration limit in island power system considering high-voltage direct current interconnections. Energies 2015, 8, 14244-14259. [CrossRef]

9. Yu, Y.; Jin, T.; Zhong, C. Designing an incentive contract menu for sustaining the electricity market. Energies 2015, 8, 14197-14218. [CrossRef]

10. Kang, H.; Chung, I.; Moon, S. Voltage control method using distributed generators based on a multi-agent system. Energies 2015, 8, 14009-14025. [CrossRef]

11. Huang, W.; Chen, T.; Chen, H.; Yang, J.; Lian, K.; Chang, Y.; Lee, Y.; Ho, Y. A two-stage optimal network reconfiguration approach for minimizing energy loss of distribution networks using particle swarm optimization algorithm. Energies 2015, 8, 13894-13910. [CrossRef]

12. Arroyo, A.; Castro, P.; Martinez, R.; Manana, M.; Madrazo, A.; Lecuna, R.; Gonzalez, A. Comparison between IEEE and CIGRE thermal behaviour standards and measured temperature on a $132-\mathrm{kV}$ overhead power line. Energies 2015, 8, 13660-13671. [CrossRef]

13. Wang, H.; Zhang, B.; Hao, Z. Response based emergency control system for power system transient stability. Energies 2015, 8, 13508-13520. [CrossRef]

14. Cai, C.; Jiang, B.; Deng, L. General dynamic equivalent modeling of microgrid based on physical background. Energies 2015, 8, 12929-12948. [CrossRef]

15. Villena, J.; Vigueras-Rodríguez, A.; Gómez-Lázaro, E.; Fuentes-Moreno, J.; Muñoz-Benavente, I.; Molina-García, A. An analysis of decentralized demand response as frequency control support under critical wind power oscillations. Energies 2015, 8, 12881-12897. [CrossRef]

16. Liao, S.; Li, Z.; Li, G.; Wang, J.; Wu, X. Modeling and optimization of the medium-term units commitment of thermal power. Energies 2015, 8, 12848-12864. [CrossRef]

17. Kim, S.; Overby, T. Optimal subinterval selection approach for power system transient stability simulation. Energies 2015, 8, 11871-11882. [CrossRef]

18. Park, S.; Jin, Y.; Yoon, Y. Designing a profit-maximizing critical peak pricing scheme considering the payback phenomenon. Energies 2015, 8, 11363-11379. [CrossRef]

19. Zhang, R.; Chu, X.; Zhang, W.; Liu, Y. Active participation of air conditioners in power system frequency control considering users' thermal comfort. Energies 2015, 8, 10818-10841. [CrossRef]

20. Moon, J.-H.; Kang, S.-H.; Ryu, D.-H.; Chang, J.-L.; Nam, S.-R. A two-stage algorithm to estimate the fundamental frequency of asynchronously sampled signals in power systems. Energies 2015, 8, 9282-9295. [CrossRef] 
21. Hong, Y.Y.; Hsieh, Y.L. Interval type-II fuzzy rule-based STATCOM for voltage regulation in the power system. Energies 2015, 8, 8908-8923. [CrossRef]

22. Jiang, Y.; Liu, C.C.; Xu, Y. Smart distribution systems. Energies 2016, 9, 297. [CrossRef]

(C) 2016 by the author; licensee MDPI, Basel, Switzerland. This article is an open access article distributed under the terms and conditions of the Creative Commons Attribution (CC-BY) license (http://creativecommons.org/licenses/by/4.0/). 